\title{
Pearl Classification: The Gia 7 Pearl Value Factors
}

Joyce Wing Yan Ho and Sally Chan Shih

$\mathrm{P}$ rized by many cultures throughout history and frequently referred to as "The Queen of Gems," pearls have long been one of the most sought-after gemstones in both the jewelry industry and the world at large. Their unique appearance and the affordability of cultured pearls in the market have allowed their popularity to grow exponentially over the years.

Pearls form in a wide variety of sizes, shapes, and colors, and there are numerous different types of pearls, both natural and cultured. This diversity created the need for a way to distinguish their various appearances and qualities. Consequently, a number of different grading systems were developed within the pearl industry over the years. The competing, often company-specific methods and coded terminology made the systems difficult to understand and employ consistently. Agreeing on a universal approach to classify pearls has remained one of the main challenges facing the pearl industry.

The idea of devising a pearl classification system similar to GIA's 4Cs system for diamonds first appeared in Gems ↔) Gemology in 1942 (Rietz, 1942a,b). The author suggested that pearls could be grouped into several categories such as gem quality, extra-fine quality, fine quality, good quality, fair quality, imperfect, and poor quality, based on several factors, namely shape, luster, surface blemishes, color distribution, and iridescence (commonly referred to as orient). This approach was further improved by GIA's Richard T. Liddicoat Jr., who in 1967 proposed a new system based on the seven pearl value factors (Liddicoat, 1967). Continued refinement eventually resulted in the development of GIA's current pearl classification system, called the GIA 7 Pearl Value Factors. This comprehensive pearl classification system offers a detailed description of the

See end of article for About the Authors and Acknowledgments.

Gems \& Gemology, Vol. 57, No. 2, pp. 135-137,

http://dx.doi.org/10.5741/GEMS.57.2.135

(C) 2021 Gemological Institute of America appearance of loose pearls, strands, and pearls in jewelry. It is a systematic approach to evaluation, through consistent methodology and common terminology that both industry professionals and consumers can understand (Zhou, 2019). This approach and the terminology of GIA's updated system have already been adopted in many parts of the pearl industry for classifying and describing pearls.

The wall chart presented here is based on a poster presentation from the 2018 GIA International Gemological Symposium (Ho and Shih, 2018). It provides the definitions and classification terminology for each of the seven value factors-size, shape, color, luster, surface, nacre, and matching - as well as digital images to illustrate various examples.

Pearls fall into one of two varieties: nacreous (resembling mother-of-pearl with lustrous nacre) and non-nacreous (such as conch or melo pearls, lacking lustrous nacre but often displaying flame structure on the surface). This system applies to nacreous pearls (see figure 1) and exclusively for the three dominant types of saltwater cultured pearls: akoya,

Figure 1. The GIA 7 Pearl Value Factors system classifies pearls according to size, shape, color, luster, surface, nacre, and matching. Composite photo by GIA staff.

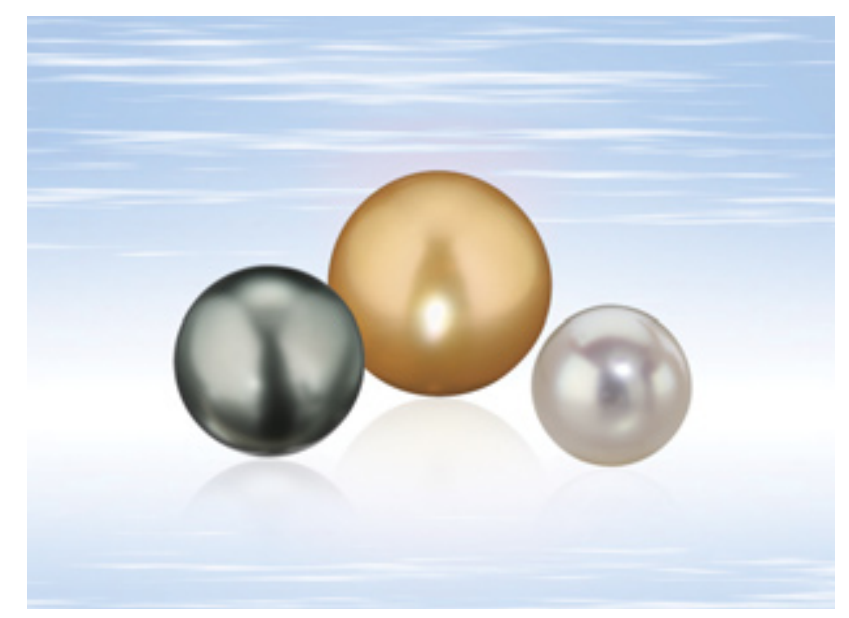




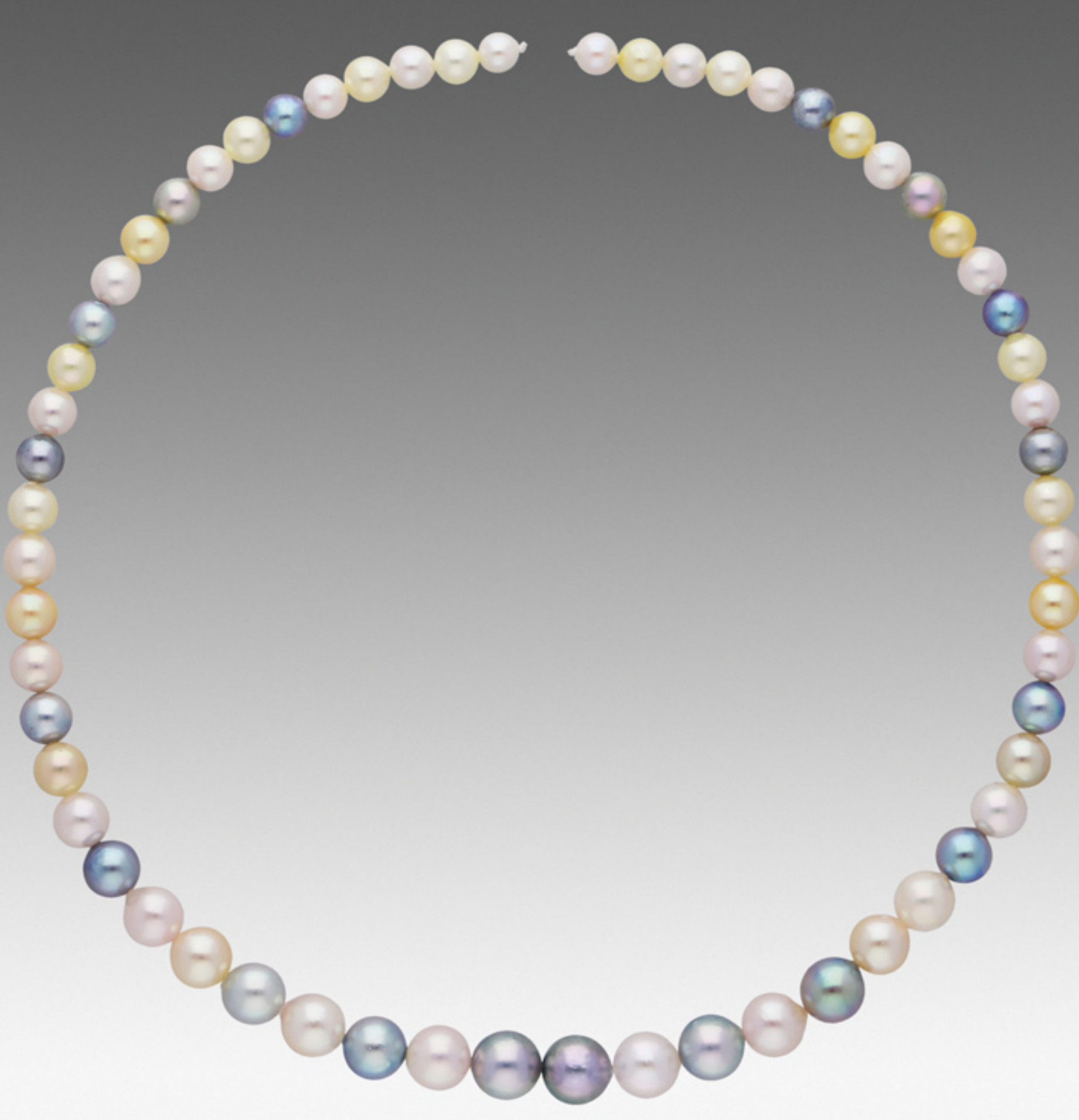

Figure 2. This akoya strand can be described using the GIA 7 Pearl Value Factors. Size: 5.51 to $8.82 \mathrm{~mm}$. Shape: Near-round. Color (Overtone): Variously colored (Variously colored). Luster: Excellent. Surface: Lightly spotted. Matching: Very good. Nacre: Acceptable. Photo by Sood Oil (Judy) Chia. 
South Sea, and Tahitian. A color scale for all types of nacreous cultured pearls and physical master sets of the three types of pearls were created to ensure a very high degree of consistency. Every GIA laboratory location that provides pearl services uses the same classification system and meticulously matched master sets to produce repeatable results. Adopting GIA's pearl classification terminology throughout the gem and jewelry industry would foster improved communication within the trade and, by default, bridge the communication and confidence gap between buyers and sellers using easily understandable language.

This wall chart is intended as a comprehensive but simplified overview of how GIA gemologists classify pearls using the GIA 7 Pearl Value Factors system (see figure 2, for example). While GIA employs an extensive set of master pearls to achieve maximum consistency in pearl classification, we hope the chart serves as a useful reference for all of our readers.
ABOUT THE AUTHORS

Ms. Ho and Ms. Shih are senior staff gemologists (pearls) at GIA in New York.

\section{ACKNOWLEDGMENTS}

The authors would like to thank GIA's New York lab staff, especially Akira Hyatt for her valuable suggestions. We greatly appreciate the help from Daniel Dell and Sood Oil (Judy) Chia with the aesthetics of the wall chart and the quality of the images.

\section{REFERENCES}

Ho J.W.Y., Shih S.C. (2018) Pearl classification: GIA's approach. Proceedings of the Sixth International Gemological Symposium, Ge G, Vol. 54, No. 3, pp. 300-301.

Liddicoat R.T. Jr. (1967) Cultured-pearl farming and marketing. $G \uplus G$, Vol. 12, No. 6, pp. 162-172.

Rietz P.C. (1942a) The classification and sales possibilities of genuine pearls. $G \uplus G$, Vol. 4, No. 1, pp. 9-12.
Rietz P.C. (1942b) The classification and sales possibilities of genuine pearls. $G \uplus G$, Vol. 4, No. 2, pp. 25-28.

Zhou C. (2019) A brief history of pearl testing through Gems 4$)$ Gemology. In Sixteenth Annual Sinkankas SymposiumPearl, Gemological Society of San Diego and Gemological Institute of America, pp. 74-83.

\section{GIA 7 Pearl Value Factors Chart}

To purchase a laminated wall chart showing GIA's approach to classifying and describing pearls, go to store.gia.edu or scan the QR code on the right.

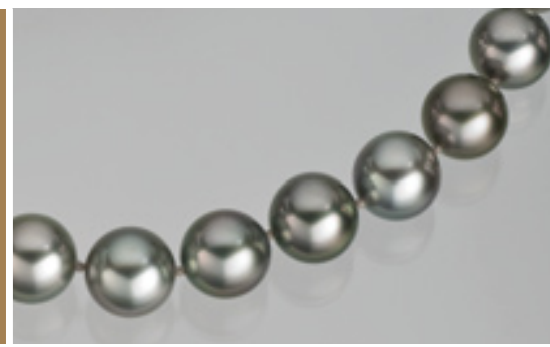

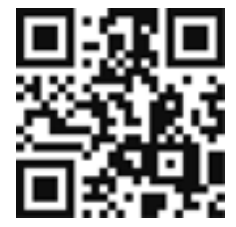

